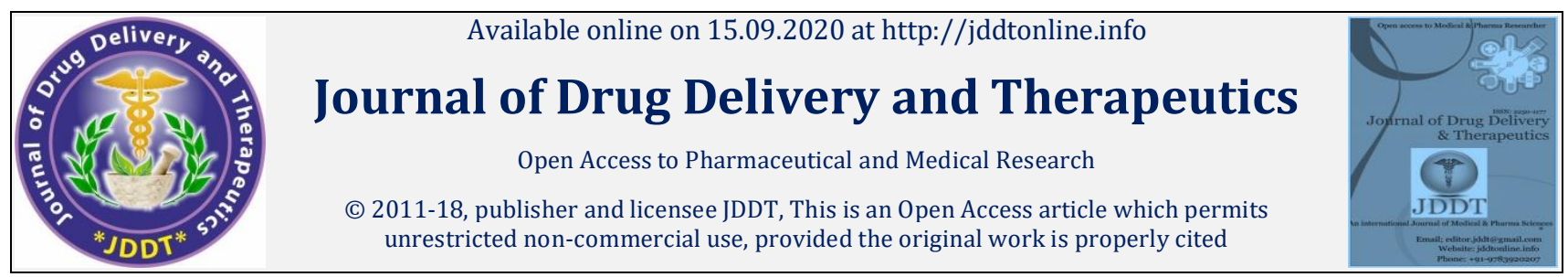

Open $\odot$ Access

Research Article

\title{
Effect of molecular interaction on the antiplasmodial efficacy of lumefantrine in amorphous polymethacrylate-urea solid solution
}

\author{
*Echezona Adaeze Chidiebere, Momoh Mumuni Audu1, Akpa Paul Achile, Ogbonna John Dike, Reginald-Opara Joy Nneji, \\ Kenechukwu Frankline Chimaobi, Uzondu Samuel Wisdom, Agbo Chinazom Precious, Ofokansi Kenneth Chibuzor, \\ Attama Anthony Amaechi
}

Drug Delivery and Nanomedecines Research group, Department of Pharmaceutics, University of Nigeria, Nsukka

\begin{abstract}
Malaria, a leading cause of mortality and morbidity in the developing world, with children aged under 5 years, accounts for $61 \%$ of all the global malaria deaths. The World Health Organization approved fixed-dose first-line artemisinin-based combination therapy (ACT) - artemether-lumefantrine - for effective malaria treatment, is challenged by poor aqueous solubility and inadequate bioavailability leading to treatment failures and emergence of resistant strains. This study focuses on evaluating novel lumefantrine (LF) polymethacrylate-urea solid solutions comprising of a retarding polymer for enhanced anti-plasmodial efficacy comparable with existing artemether-lumefantrine combination therapy. Lumefantrine polymethacrylate-urea solid solutions were prepared by solvent evaporation and characterized by differential scanning calorimetry (DSC), and dissolution studies. In vivo anti-plasmodial activity was determined by measuring the schizonticidal activity of Plasmodium berghei-infected mice using the Peter's 4-day curative test and the safety of the solid solutions was tested in major organs implicated in malaria. The solid state characterizations confirmed the formation of amorphous lumefantrine polymethacrylate-urea solid solutions. There was greater drug release from the matrix polymer in acidic than basic biorelevant media, with release kinetics following the Higuchi order. Interestingly, the reduction in parasitaemia caused by the lumefantrine polymethacrylate-urea formulations $(72.3$ and $81.27 \%)$ for ternary and quaternary systems, batches SDA3 and SDB3, respectively) were significantly higher (p < 0.05 ) and more sustained than lumefantrine pure powder, but with comparable efficacy to the commercial brand-Coartem ${ }^{\circledR}$. The formulation was stable over a period of 6 months. Thus, this study provides useful information on developing sustained lumefantrine formulation with improved solubility and antiplasmodial efficacy.
\end{abstract}

Keywords: Solid dispersion, lumefantrine, solubility, parasitaemia reduction, eudragit polymer, Urea.

Article Info: Received 09 July 2020; $\quad$ Review Completed 14 Aug 2020; $\quad$ Accepted 21 Aug 2020; $\quad$ Available online 15 Sep 2020

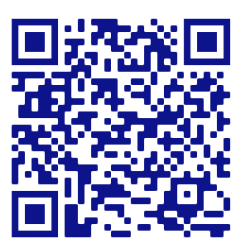

\section{Cite this article as:}

Echezona AC, Momoh MA, Akpa PA, OgbonnaJD, Reginald-Opara JN, Kenechukwu FC, Uzondu SW, Agbo CP, Ofokansi KC, Attama AA, Effect of molecular interaction on the antiplasmodial efficacy of lumefantrine in amorphous polymethacrylateurea solid solution, Journal of Drug Delivery and Therapeutics. 2020; 10(5):56-69

http://dx.doi.org/10.22270/jddt.v10i5.4279

Echezona Adaeze Chidiebere, Drug Delivery and Nanomedecines Research group, Department of Pharmaceutics, University of Nigeria, Nsukka

\section{INTRODUCTION}

Malaria, a common parasitic vector-borne poverty-related disease caused by the bite of infected mosquitoes, affects the quality of life of millions of people in malaria endemic regions of the world and is the leading cause of mortality and morbidity in the developing world. The world health organization (WHO) estimated 219 million cases in 87 countries associated with 435000 deaths as of 2017, where children and pregnant women are primarily at risk ${ }^{1}$. According to Ashley et $a l^{2}$, the onus of malaria is largely felt by Africans, although the access to effective treatment and diagnosis has improved in recent times, the menace of emerging antimalarial resistance is extremely worrying. The antimalarial agent lumefantrine, is potent and is commercially available in combination with artemether in the ratio of $6: 1$ in artemisinin-based combination therapies (ACTs) for the treatment of severe multi-resistant and cerebral malaria ${ }^{3}$. The combination is active against Plasmodium vivax as well as against chloroquine-sensitive and chloroquine-resistant strains of Plasmodium falciparum $^{3,4}$. Here, the complementarities rest on the fact that while artemether peak plasma concentration is reached approximately 2 hours after dosing, lumefantrine starts after a lag period of up to 2 hours, with peak plasma concentration reached approximately 6-8 hours after dosing. Hence, artemether first acts on the malaria parasites and reduces the parasite burden instantly, later lumefantrine acts on the remaining parasites 5 . Although lumefantrine is an active drug, its low and variable oral bioavailability owning to poor 
solubility limits its therapeutic potential ${ }^{3}$ and results in subtherapeutic plasma concentration ${ }^{6}$. New formulation strategies has been applied to obviate the problems such as salt formation, particle size reduction, pro drug formulation, solid state modification, complexation, solid lipid nanoparticles and solid dispersions $(\mathrm{SD})^{7}$. In recent times, the SD has become one of the best approaches used to improve the solubility, in vitro dissolution rates, and thus the bioavailability of poorly water-soluble drugs 8-10, where crystalline drugs are converted to amorphous forms using hydrophilic carriers ${ }^{11}$.

In the present study, solid dispersions of lumefantrine were prepared with the goal of improving drug solubility, in vitro dissolution rate, and bioavailability as well as sustaining its release. Several works have already been carried out to improve the solubility and/or bioavailability of lumefantrine alone/in ACT3,12-14 which will ultimately enhance their antimalarial activity in ACT. Gahoi et al ${ }^{3}$ established the fact that wet milling technique used to prepare the nanopowder of lumefantrine enhances the dissolution rate. Selfnanoemulsifying drug delivery systems for LF prepared using oleic acid and Cremophor EL was found to enhance its dissolution rate ${ }^{12}$. Patel et al13 noted that despite the advantage of faster in vitro dissolution rate of lumefantrine, these studies lack in vivo pharmacokinetic information to validate it.

A great deal of research has been conducted by earlier researchers to improve the aqueous solubility and/or bioavailability of lumefantrine 15,16 , but there is paucity of information in the literature on the development of lumefantrine in amorphous polymethacrylate-urea solid solution of lumefantrine. We hypothesized that amorphous polymethacrylate-urea solid solutions of lumefantrine would improve its aqueous solubility and bioavailability with resulting enhancement of the antimalarial activity of the drug. Thus, the purpose of this study is to prepare solid dispersion systems of lumefantrine using polymethacrylate polymers such Eudragit ${ }^{\circledR}$ RS100 and E100 and a hydrophilic carrier, urea, so as to determine the benefits of this system in the solubility and dissolution properties of the drug, as well as investigate the presentation of LF-SDs in vivo.

\section{MATERIALS AND METHODS}

\section{Materials}

The lumefantrine sample was obtained from Hangzhou Dayangchem. Co. Limited, (Hangzhou, Peoples Republic of China), Eudragit ${ }^{\circledR}$ RS100 and E100 were kindly provided by Rohm (Germany). Other materials include urea (SD fine chemicals Ltd., Mumbai, India), chloroform, ethanol and acetone (Sigma-Aldrich, Steinheim, Germany), polycarbonated dialysis memebrane (MWC06000-8000) (Spectrum Labs, Breda, The Netherlands), commercial antimalarial tablet containing lumefantrine used was Coartem $^{\circledR}$ (Novartis Pharmaceuticals). The biorelevant media[simulated intestinal fluid (SIF) ( $\mathrm{pH}$ 6.8) and simulated gastric fluid (SGF) ( $\mathrm{pH}$ 1.2)] were prepared without pepsin and pancreatic, respectively. Distilled water was obtained from the University of Nigeria Lion Water and used throughout the study. All other materials and solvents were of analytical grade.

\section{Animals}

All animal experiments were performed in accordance with the National Institute of Health guidelines on the principles of laboratory animal care (National Institute of Health Publication 85-23, revised 1996) and were approved by the Institution Animal Care and Use Committee of the University of Nigeria, Nsukka. Albino Wistar mice of both sexes and weighing 14.8 - $29.3 \mathrm{~g}$ (obtained from the Faculty of Veterinary Medicine, University of Nigeria Nsukka) were used for the study. The animals were housed in propylene cages maintained under standard conditions (illumination cycle of $12 \mathrm{~h}$ dark and $12 \mathrm{~h}$ light, $25 \pm 5{ }^{\circ} \mathrm{C}$ and $45-60 \%$ humidity). They were fed on 'chick marsh' (Top Feed, Nigeria) and provided free access to water. They were allowed to acclimatize to these conditions for a period of two weeks. Plasmodium berghei was hosted by donor mice from the Nigerian Institute of Medical Research (NIMR), Lagos. They were used for the in vivo study.

\section{Methodology}

\section{Preparation of lumefantrine solid dispersions}

LF solid dispersions (SD) were prepared by the solvent evaporation method. Briefly, accurate quantity of the drug and polymers were weighed and added to a mixture of chloroform, acetone and ethanol (1:4:3) in a $200 \mathrm{ml}$ volumetric flask. The mixture were allowed to dissolve after shaking, this was followed by gentle heating in a rotary evaporator at temperature $40{ }^{\circ} \mathrm{C}$ until all the solvents were removed, using a modified solvent evaporation technique ${ }^{17}$. The residues were transferred to an aluminum pan, dried at room temperature, pulverized in a mortar and sieved through a 100-mesh screen. The resultant ternary and quaternary solid dispersions were packed in screw cap containers and stored in desiccators for further use. SDA-1 to SDA-5 stand for the ternary LF SDs containing Eudragit ${ }^{\circledR}$ RS100 and Eudragit ${ }^{\circledR}$ E100 respectively while those of the ternary SDs were called SDB-1 to SDB-5 and contained urea in addition to the above-mentioned polymers. All the SDs was properly labeled as shown in Table 1 .

Table 1: Formulation compositions of the solid dispersions

\begin{tabular}{|c|c|c|c|c|c|}
\hline Formulation code & $\begin{array}{l}\text { Ratio of Drug, Eudragit } \\
\text { E100, Eudragit RS } 100 \\
\text { and Urea }\end{array}$ & $\begin{array}{l}\text { Lumefantrine } \\
\text { (g) }\end{array}$ & $\begin{array}{l}\text { Eudragit E } \\
100(\mathrm{~g})\end{array}$ & $\begin{array}{ll}\text { Eudragit } & \text { RS } \\
100(\mathrm{~g}) & \end{array}$ & Urea(g) \\
\hline SDA-1 & $1: 1: 1$ & 0.12 & 0.12 & 0.12 & - \\
\hline SDA-2 & $1: 1: 2$ & 0.12 & 0.12 & 0.24 & - \\
\hline SDA-3 & 1:2:1 & 0.12 & 0.24 & 0.12 & - \\
\hline SDA-4 & $1: 1: 3$ & 0.12 & 0.12 & 0.36 & - \\
\hline SDA-5 & $1: 3: 1$ & 0.12 & 0.36 & 0.12 & - \\
\hline SDB-1 & 1:1:1:1 & 0.12 & 0.12 & 0.12 & 0.12 \\
\hline SDB-2 & $1: 1: 2: 1$ & 0.12 & 0.12 & 0.24 & 0.12 \\
\hline SDB-3 & $1: 2: 1: 1$ & 0.12 & 0.24 & 0.12 & 0.12 \\
\hline SDB-4 & $1: 1: 3: 1$ & 0.12 & 0.12 & 0.36 & 0.12 \\
\hline SDB-5 & 1:3:1:1 & 0.12 & 0.36 & 0.12 & 0.12 \\
\hline
\end{tabular}




\section{Characterization of the solid dispersions}

\section{Determination of percentage yield}

The practical yields of the solid dispersions were determined to evaluate the efficiency of the method of preparation. The percentage yields were calculated using the formula below:

Percentage $(\%)$ yield $=$

$$
\frac{\text { Weight of prepared solid dispersions }}{\text { Theoritical yield }} \times 100
$$

Eqn. 1

\section{Estimation of drug content}

Solid dispersions equivalent to $30 \mathrm{mg}$ of the drug were taken and dissolved in $100 \mathrm{ml}$ of methanol. The solution was shaken vigorously and filtered. Then the filtrate was suitably diluted, and the drug content was analyzed against a blank of methanol using a UV/ Visible spectrophotometer (Jenway 6405 spectrophotometer, UK) at $335 \mathrm{~nm}$. The percentage of drug present in the solid dispersions was calculated with respect to a standard plot. The actual drug content was calculated using the following equation:

Drug content $(\%)=$

$\frac{\text { Actual amount of drug in solid dispersion }}{\text { Theoretical amount of drug in solid dispersion }} \times 100$

Eqn. 2

\section{Stability studies}

The stability of the different batches of lumefantrine SDs was assessed according to International Conference of Harmonization (ICH) guidelines $\left(40 \pm 2{ }^{\circ} \mathrm{C}\right.$ and $\left.75 \pm 5 \% \mathrm{RH}\right)$. The formulations were packaged in amber-colored bottle in a humidity chamber and after $24 \mathrm{~h}$, three and six months, samples were withdrawn and assayed for drug content.

\section{Saturation Solubility studies}

This was evaluated by adding an excess amount of LF (25 $\mathrm{mg} / \mathrm{ml}$ ), the binary and ternary SDs in $2.5 \mathrm{ml}$ of distilled water. The samples were agitated in a thermostatically controlled water shaker bath (Equitron, Medica Instrument Mfg. Co., Mumbai, India) at $50 \mathrm{rpm}$ for $72 \mathrm{~h}$ at $37 \pm 0.5{ }^{\circ} \mathrm{C}$ after which the samples were centrifuged (Sigma 3K30, sigma Laborzentrifugen $\mathrm{GmbH}$, Germany) at 10,000 rpm for $20 \mathrm{~min}$. The supernatant was filtered through a Whatman filter paper. The filtered solutions were diluted with methanol and evaluated using a UV/ Vis spectrophotometer (Jenway 6405 spectrophotometer, UK) at $335 \mathrm{~nm}$.

\section{Determination of morphology}

Morphology characteristics of the binary and ternary SDs were obtained using a phase-contrast microscope (Motic B3, Carlsbad, CA, USA) at a magnification of $\mathrm{x} 400$. Photomicrographs of all the batches of SDs were captured using Motic ${ }^{\circledR}$ image Software (Motic, Xiamen China).

\section{Solid state characterization by differential scanning calorimetry}

Thermal analysis was performed on the drug sample, Eudragit ${ }^{\circledR}$ RS100 and E100, urea and the SDs using differential scanning calorimeter ((Shimadzu DSC60 apparatus, Shimadzu Corporation, Kyoto Japan). Briefly, $5 \mathrm{mg}$ of each sample was placed in an aluminum crucible, sealed and heated at a scanning rate of $10{ }^{\circ} \mathrm{C} / \mathrm{mins}$ with a temperature range of $25-250{ }^{\circ} \mathrm{C}$ under stream of nitrogen.

\section{In vitro release studies}

In vitro drug release study of the different batches of SDs was performed in $500 \mathrm{ml}$ each of SGF and SIF, with the temperature and speed of rotation of each medium maintained at $37 \pm 1^{\circ} \mathrm{C}$ and $50 \mathrm{rpm}$ respectively. A quantity of the SDs containing $120 \mathrm{mg}$ (lumefantrine) was weighed separately and placed in a polycarbonated dialysis membrane (MWCO 6000 - 8000, Spectrum Labs, Breda, The Netherlands) which was pre-treated by soaking in distilled water for $5 \mathrm{~h}$ prior to use. The formulated SDs was placed in the dialysis membrane containing $3 \mathrm{ml}$ of the dissolution medium, securely tied with a thermo-resistant thread and then immersed in the dissolution medium under agitation provided by the bead at $50 \mathrm{rpm}$. At predetermined time interval of $1 \mathrm{~h}, 5 \mathrm{ml}$ portions of the dissolution medium were withdrawn, filtered and the absorbances determined at a wavelength of $335 \mathrm{~nm}$ using a UV/VIS Spectrophotometer ((Unico 2012, England). The amount of drug released at each time point was calculated with reference to the standard plot of lumefantrine. To maintain sink conditions, $5 \mathrm{ml}$ of fresh medium was replaced after each withdrawal.

The in vitro dissolution study of the commercial sample of lumefantrine using the combination drug of artemether and lumefantrine (coartem ${ }^{\circledR}$ ) and the pure drug (lumefantrine) was also performed for purpose of comparison. The kinetics and mechanism of drug release of the SDs from the membrane were determined using different models. The amount of drug released from the formulated dispersions at different time intervals were fitted into zero order, Higuchi and Ritger-Peppas kinetic models whose equations are shown below as Eqs. (3), (4) and (5), respectively.

$$
\begin{array}{lr}
\mathrm{Qt}=\mathrm{Q}_{0}+\mathrm{k}_{0} \mathrm{t} & \text { Eqn } 3 \\
\mathrm{Q}=\mathrm{KH}_{\mathrm{H}} \mathrm{t}^{1 / 2} & \text { Eqn } 4 \\
\mathrm{~F}=(\mathrm{Mt} / \mathrm{M})=\mathrm{Kmt}^{\mathrm{n}} & \text { Eqn } 5
\end{array}
$$

where $\mathrm{Q}$ is the cumulative amount of drug at time, $\mathrm{t}, \mathrm{Qt}$ is the amount of drug dissolved at time, $t, Q_{0}$ is the initial amount of drug in solution, $\mathrm{k}_{\mathrm{H}}, \mathrm{K}_{\mathrm{M}}$ and $\mathrm{k}_{0}$ are the Higuchi, KosmeyerPepas and zero order rate constants, respectively. The linearity of these plots was determined by their $\mathrm{R}^{2}$ values and the plot with the highest linearity was taken as that which described the kinetics and mechanism of drug release.

\section{In vivo schizontocidal activity}

Evaluation of the curative potential of formulated SDs against established Plasmodium infection was carried out according to standard protocols as described by Ryley and Peters ${ }^{18}$. Briefly, the mice were divided into fourteen groups of five mice per group. Blood of the donor mice was collected by cardiac puncture and diluted with physiological salt (normal saline) to give a concentration of $10^{8}$ parasitized erythrocytes per ml. A $0.2 \mathrm{ml}$ volume of the donor mouse erythrocyte equivalent to $2 \times 10^{7}$ parasitized erythrocytes was injected intraperitoneally into each of the 70 experimental mice on day $1\left(\mathrm{D}_{1}\right)$, and left untreated until the fourth day $\left(\mathrm{D}_{4}\right)$ post inoculation. Ab initio, on day 0 of the test $\left(D_{0}\right)$, percentage parasitemia and red blood cell count, of the donor mice were determined by Giemsa-stained thin blood smear of the donor mice and improved Neubauer Counting Chamber, respectively. Post-inoculation, all treatments were given orally per day for 3 days ( $\left.D_{4}-D 6\right)$. Groups $A_{3}, A_{5}$ and $\mathrm{B}_{3}, \mathrm{~B}_{5}$ received $24 \mathrm{mg} / \mathrm{kg}$ of SD formulations once daily from each batch of (SDA-3, SDA-5) and (SDB-3, SDB-5) formulations respectively. Group $\mathrm{C}$ received $24 \mathrm{mg} / \mathrm{kg}$ of pure drug once daily. Group D received 4 and $24 \mathrm{mg} / \mathrm{kg}$ of commercial fixed combination dose of artemetherlumefantrine (coartem ${ }^{\circledR}$ ) once daily. Group E were administered with $0.3 \mathrm{ml} / \mathrm{kg}$ body weight of normal saline. The animals were evaluated for packed cell volume (PCV), haemoglobin count $(\mathrm{Hb})$, white blood cell count, and red 
blood cell count (RBC). These parameters were also determined before treatment, after parasite inoculation and post treatment. On day 7 (D7), each mouse was tail-bled and a thin blood film was made on a microscopic slide. The efficacy of the developed formulation was determined by monitoring the mean percentage parasitaemia curative activity against time. Percentage parasitaemia was calculated based on the parasite count pre- treatment and posttreatment using the formula:

$\%$ Parasitaemia $=$

(Average pretreatment-Average posttreatment)parasitemia Average pretreatment parasitaemia

Eqn. 6

\section{Histopathological studies}

\section{Tissue preparation}

The surviving experimental animals were sacrificed after seven days post treatment of the study. Gross lesions were recorded as observed during the post mortem examination. Sections of the liver and kidney were collected for histopathological examination. The tissues were fixed in 10 $\%$ phosphate buffered formalin for a minimum of $48 \mathrm{~h}$ until commencement of tissue processing. The tissues were subsequently trimmed, dehydrated in 4 grades of alcohol $(70,80,90$ and $100 \%)$, cleared in 3 grades of xylene and embedded in molten wax. On solidifying, the blocks were cut into $5 \mu \mathrm{m}$ thick tissue sections using a rotary microtome, floated in water bath and incubated at $60{ }^{\circ} \mathrm{C}$ for 30 mins. The $5 \mu \mathrm{m}$ thick sectioned tissues were subsequently cleared in 3 grades of xylene and rehydrated in 3 grades of alcohol $(90$, 80 and $70 \%$ ). The sections were then stained with Hematoxylin for 15 mins. Bluing was done with ammonium chloride and differentiation was done with $1 \%$ acid alcohol before counterstaining with Eosin. Permanent mounts were made on degreased glass slides using a mountant; a mixture of Distyrene, a plasticizer, and xylene (DPX).

\section{Slide examination and photomicrography}

The prepared slides were examined with a Motic ${ }^{\mathrm{TM}}$ camera mounted on a compound light microscope using $x 4, \mathrm{x} 10$ and $\mathrm{x} 40$ objective lenses. The photomicrographs were taken using a Motic ${ }^{\mathrm{TM}} 9.0$ megapixels microscope camera at $\mathrm{x} 100$ and $\mathrm{x} 400$ magnifications.

\section{Data and statistical analysis}

Results are expressed as mean \pm standard deviation. For group comparisons, One-way ANOVA using excel and graph pad prism was employed, and p-values $\leq 0.05$ were considered statistically significant.

\section{RESULTS}

\section{Practical yield of solid dispersions}

The practical yields of the SD fell within the range of 59.8 \pm $0.97 \%$ and $97.5 \pm 0.56 \%$. This indicates the effectiveness of the method adopted for the formulation of the SDs. SDA-4 and SDA-3 formulations of the binary batches had the highest and least practical yields respectively while SDB1 and SDB- 2 formulations of ternary batches had the highest and least practical yields respectively. The yield increased as the proportion of each polymer in the dispersion increased. The yield of the solid dispersions in the quaternary batch was higher than the ternary batch when the two polymer blends were incorporated in equal proportions of the polymers as a carrier system in the formulation of solid dispersions.

Table 2: Percentage yields of solid dispersions, their solubility and drug content (DC) at 0, 3 and 6 months

\begin{tabular}{|c|c|c|c|c|c|c|}
\hline Batch code & $\begin{array}{l}\text { Percentage } \\
\text { practical yield } \\
(\%)\end{array}$ & $\begin{array}{l}\text { Solubility } \\
(\mathrm{mg} / \mathrm{ml})\end{array}$ & $\begin{array}{l}\text { Particle } \\
\text { (um) }\end{array}$ & Initial (DC) (\%) & $\begin{array}{ll}\text { DC after } & 3 \\
\text { months (\%) }\end{array}$ & $\begin{array}{lr}\text { DC after } & 6 \\
\text { months(\%) }\end{array}$ \\
\hline SDA-1 & $79.7 \pm 2.31$ & $0.26 \pm 0.90$ & $189.4 \pm 3.03$ & $59.9 \pm 0.19$ & $59.0 \pm 0.25$ & $58.8 \pm 0,87$ \\
\hline SDA-2 & $72.3 \pm 0.38$ & $0.25 \pm 0.17$ & $267.5 \pm 2.65$ & $58.5 \pm 0.20$ & $57.8 \pm 1.05$ & $56.2 \pm 0.61$ \\
\hline SDA-3 & $59.8 \pm 0.97$ & $0.28 \pm 0.24$ & $193.8 \pm 1.14$ & $43.2 \pm 0.34$ & $42.0 \pm 1.25$ & $41.9 \pm 0.20$ \\
\hline SDA-4 & $90.0 \pm 0$ & $0.26 \pm 0.20$ & $452.3 \pm 2.31$ & $49.1 \pm 0.24$ & $48.0 \pm 1.58$ & $47.5 \pm 0.23$ \\
\hline SDA-5 & $83.6 \pm 0.62$ & $0.40 \pm 0.45$ & $224.2 \pm 0.34$ & $56.2 \pm 0.12$ & $55.7 \pm 1.22$ & $55.1 \pm 0.21$ \\
\hline SDB-1 & $97.5 \pm 0.56$ & $0.88 \pm 2.54$ & $251.2 \pm 3.43$ & $52.5 \pm 0.18$ & $50.0 \pm 1.65$ & $49.7 \pm 0.17$ \\
\hline SDB-2 & $68.0 \pm 0.65$ & $0.80 \pm 3.00$ & $312.9 \pm 1.21$ & $53.3 \pm 0.71$ & $53.0 \pm 1.35$ & $52.4 \pm 0.43$ \\
\hline SDB-3 & $91.4 \pm 0.74$ & $0.89 \pm 1.40$ & $274.3 \pm 2.35$ & $61.4 \pm 0.27$ & $59.5 \pm 0.35$ & $59.0 \pm 0.45$ \\
\hline SDB-4 & $81.7 \pm 2.13$ & $0.90 \pm 2.10$ & $514.1 \pm 3.65$ & $60.2 \pm 0.50$ & $58.5 \pm 0.16$ & $58.0 \pm 1.12$ \\
\hline SDB-5 & $89.0 \pm 0.20$ & $0.65 \pm 1.22$ & $212.2 \pm 0.72$ & $51.5 \pm 0.45$ & $51.0 \pm 0.76$ & $50.0 \pm 0.33$ \\
\hline Pure drug (LF) & & $0.11 \pm 0.60$ & - & & & \\
\hline
\end{tabular}

\section{Drug contents}

The lumefantrine content in all the solid dispersions were found to be in the range of $43-61 \%$ approximately, as shown in Table 2. However, batch SDB-3 solid dispersions of the quaternary batch showed the highest drug content while batch SDA-4 solid dispersion of the ternary batch had the least drug content. It is also discernible from the results that the quaternary batches of SDs (SDB-1 to SDB-5) had better drug entrapment than the ternary system (batches SDA-1 to SDA-5).

\section{Stability studies of the formulation}

The results of the stability studies carried out on the different batches of the SDs are shown in Table 2. It is evident from the results that there was an insignificant ( $p>$ 0.05) decrease in the content of lumefantrine after six months of storage. In typical case, the drug content obtained for the ternary (SDA1-SDA5) and quaternary batch (SDB1SDB5) SDs are as follows: SDA-1 (59.9-59-58.8), SDA-2 (58.5-57.8-56.2), SDA-3 (43.2-42-41.9), SDA-4 (49.1-4847.4), SDA-5 (56.22-55-55), SDB-1 (52.5-50-49.8), SDB-2 (53.3-53-52.4) SDB-3 (61.47-59.8-59), SDB-4 (60.1-58.5-58), and SDB-5 (51.5-51-50) after $24 \mathrm{~h}, 3$ months and 6 months of storage respectively as shown in the values in parenthesis.

\section{Saturated Solubility of the formulations}

Table 2 depicts the mean aqueous solubility profile of the SDs in relation to that of the pure drug. As can be seen, the formulations revealed an increase in solubility as compared to lumefantrine pure drug sample in water. However, the ternary batches (SDA-1 to SDA-5) were observed to have 
enhanced the solubility but to a less significant amount when compared to the quaternary batches (SDB-1 to SDB-5).

\section{Morphology, surface Characteristics and particle size}

The phase-contrast microscope was adopted to determine the morphology of the lumefantrine SDs. The SDs on visual examination was powdery and light yellow in color. The photomicrographs showing the morphology of the different SD formulations are shown in Fig. 1. The photomicrographs
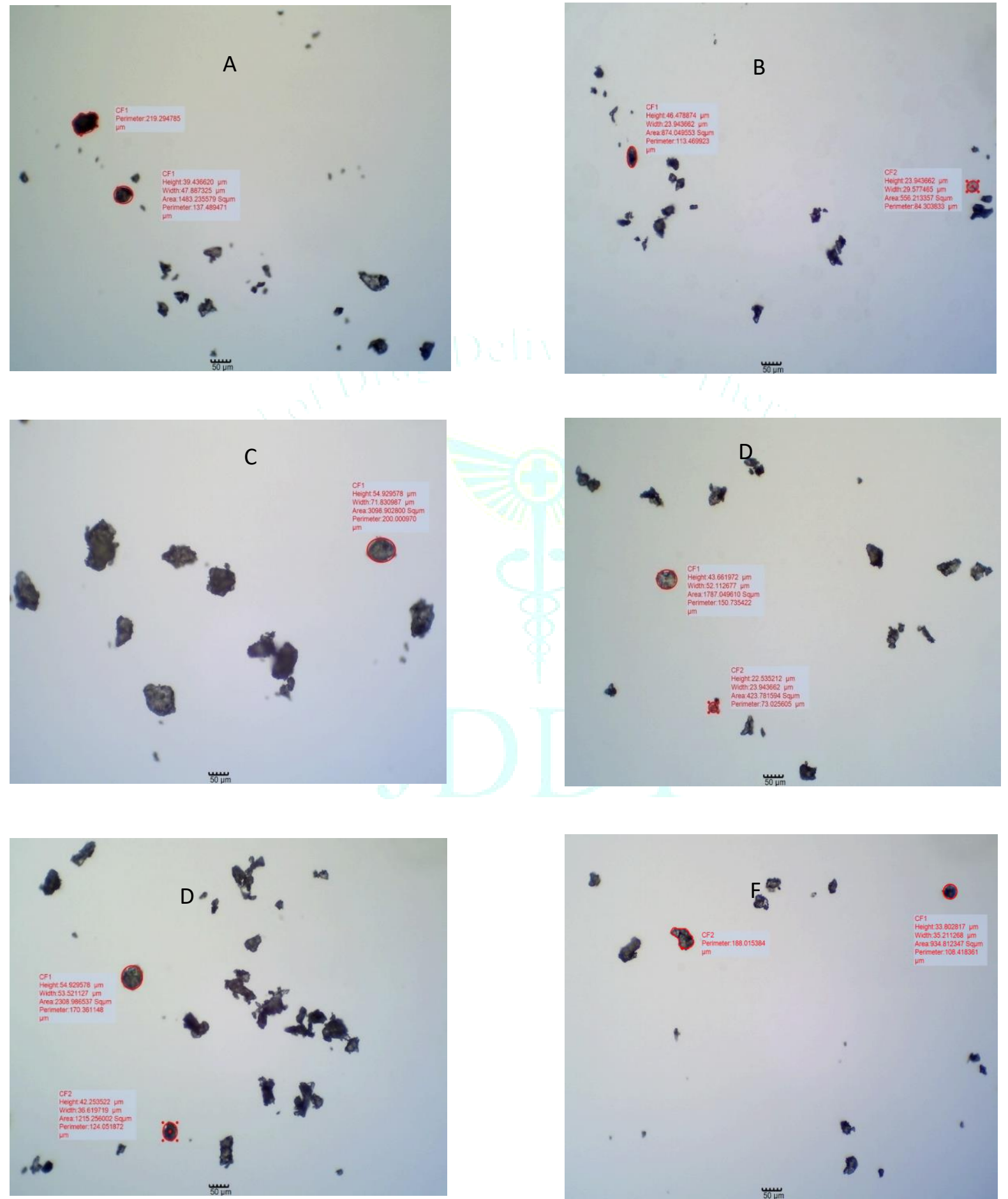

Figure 1(A-F): Photomicrographs A to F showing the ternary and quaternary SDs of A (SDA- 1), B(SDA-3), C (SDA-5), D (SDB1), E (SDB-3) and F (SDB-5) Lumefantrine SDs, respectively. Key: SDA-1, SDA-3, and SDA-5, represents lumefantrine containing Eudragit RS100, Eudragit E100 alone while SDB-1, SDB-3, and SDB-5 contained Urea in addition to the above mentioned polymers in this ratios $1: 1.1,1: 2: 1,1: 3: 1,1: 1: 1: 1,1: 2: 1: 1$ and $1: 3: 1: 1$, respectively. 


\section{Thermal analysis}

Prior to the DSC study, melting point of the lumefantrine used was determined to be in the range of $160-165^{\circ} \mathrm{C}$. The DSC thermograms of lumefantrine, Eudragit ${ }^{\circledR}$ E100, Eudragit ${ }^{\circledR}$ RS100, urea and different batches (SDA-3, SDA-5,
SDB-3 and SDB-5) of lum: E100:RS100: Ureas SDs in superpositions is shown in Figs. 2. The thermograms of the pure drug sample, Eudragit ${ }^{\circledR}$ RS100, Eudragit ${ }^{\circledR}$ E100 and urea showed sharp endothermic peaks at $161.90{ }^{\circ} \mathrm{C}, 217.73$ ${ }^{\circ} \mathrm{C}, 91^{\circ} \mathrm{C}$ and $110.13^{\circ} \mathrm{C}$ respectively indicating the melting points of each substance.

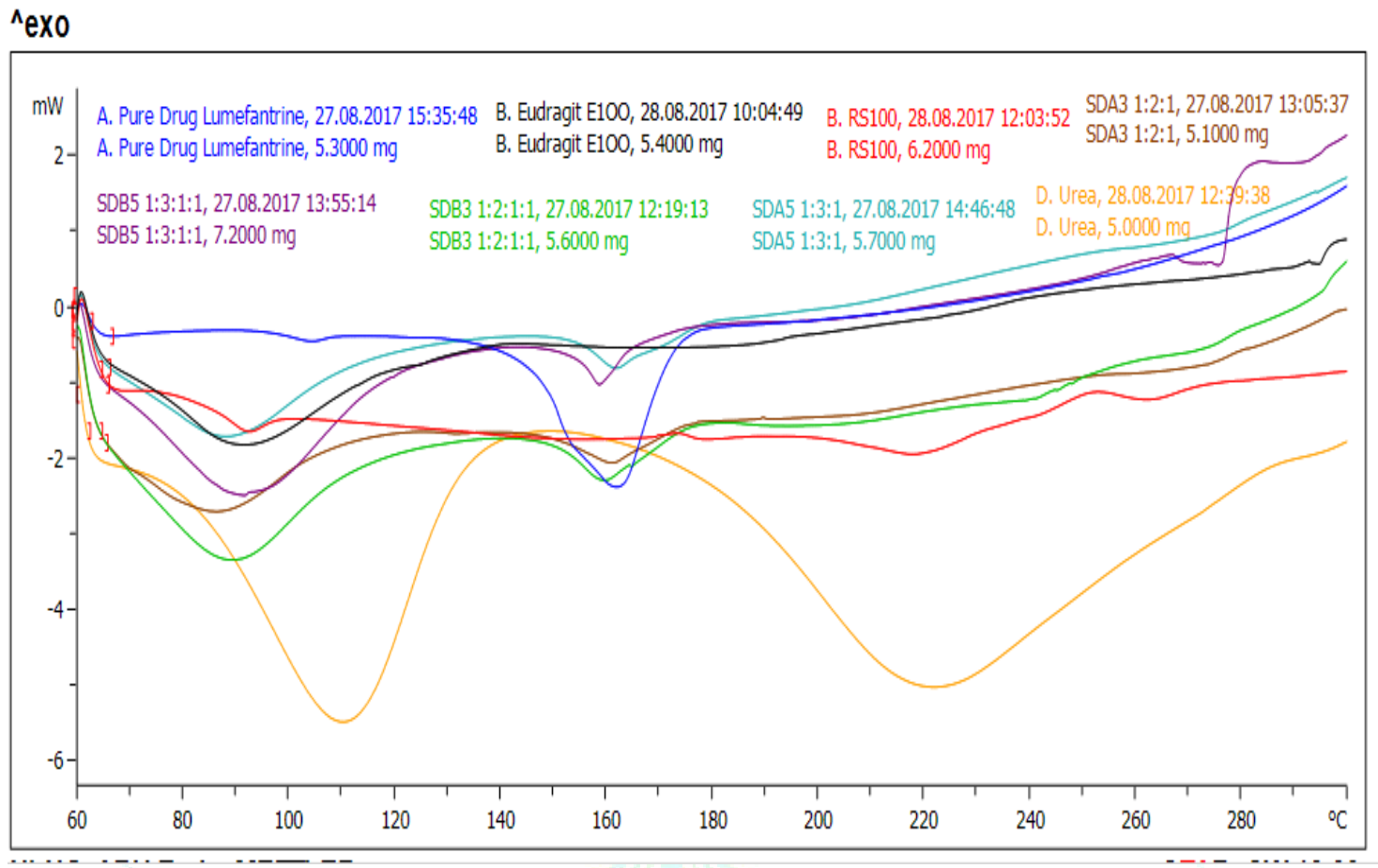

Fig 2: DSC thermograms of the pure samples (Lumefantrine, E100, RS100 and Urea), SDA3, SDA5, SDB3, and SDB5.

\section{In vitro drug dissolution studies}

The dissolution studies of pure lumefantrine, the ternary systems (SDA-3 and SDA-5), quaternary systems (SDB-3 and SDB-5), lumefantrine, and the commercially available product were performed in simulated gastric fluid $(\mathrm{pH} 1.2)$ and simulated intestinal fluid (pH 7.4) and results shown in Figs. 3 ( $a$ and b) respectively. Based on the results, drug release was higher in SGF than in SIF. In the SGF release media, a biphasic drug release was observed in which 15 $20 \%$ of the drug was released in the first hour which represents the amounts that adhered weakly to the surface of the formulated SDs and subsequent extended release for the next $12 \mathrm{~h}$ which also represents the amount that was trapped into the core (matrix) of the SDs. In SGF, the formulations also showed a significant $(\mathrm{p}<0.05)$ and more rapid dissolution compared to the pure drug but when compared to the commercially available product (coatem ${ }^{\circledR}$ ), the commercial sample showed more dissolution although insignificant $(p>0.05)$ when compared to the SDs. The SDs of the quaternary batches formulated with urea showed higher release as compared to the ternary batches due to its hydrophilic nature. Batch SDB-3 of the quaternary batches had highest percentage drug release of $23.50 \%$ and $78 \%$ in SIF, ( $\mathrm{pH} 7.4$ ) and SGF, ( $\mathrm{pH} 1.2$ ) respectively, while batch SDA-3 of the ternary batches had the least percentage (\%) drug release of $12.58 \%$ and $65.7 \%$ in SIF, (pH 7.4) and SGF, (pH 1.2) respectively. 

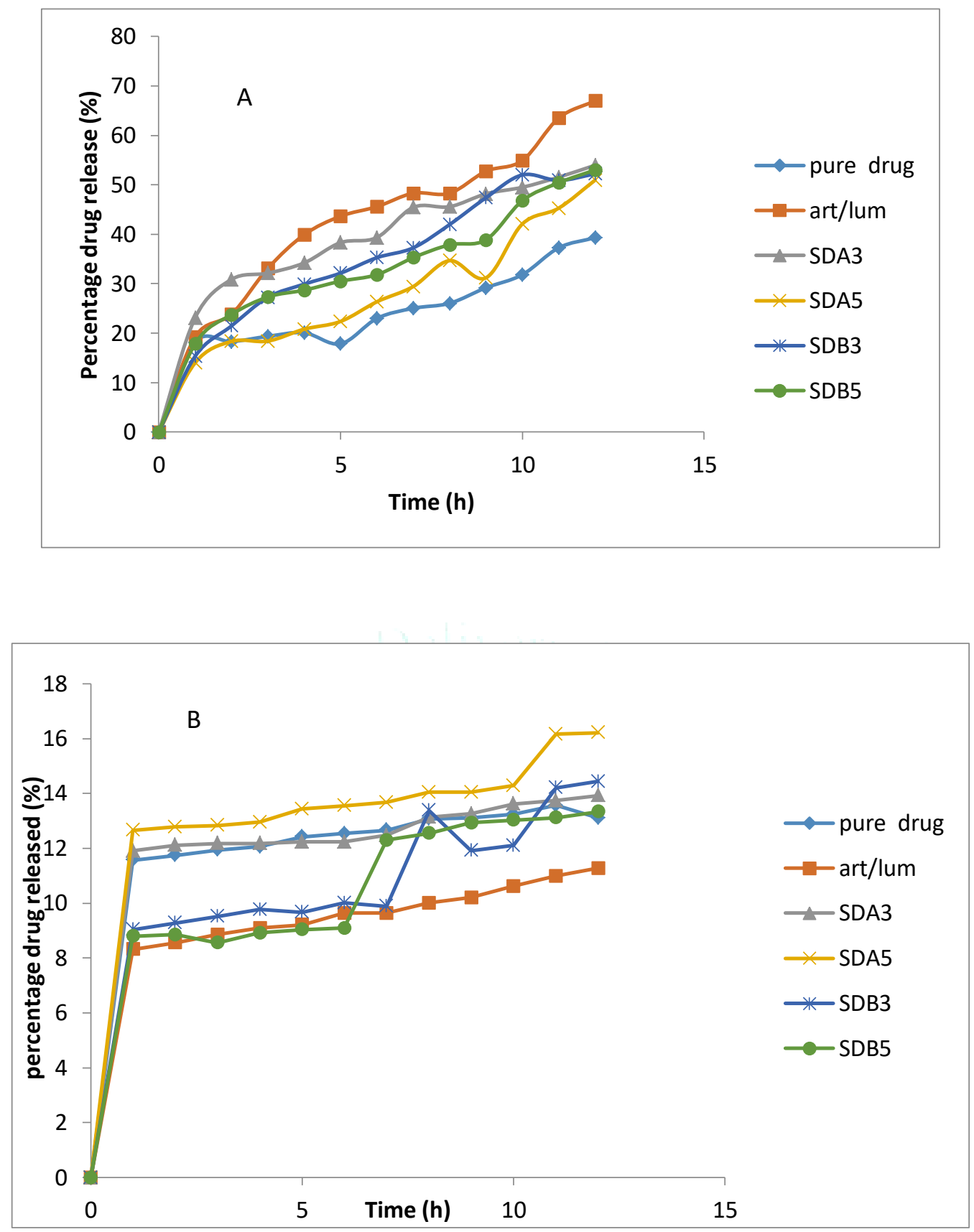

Fig.3 (A and B): Drug release profile of lumefantrine, its solid dispersions and market brand (Coartem ${ }^{\circledR}$ ) in SGF, pH 1.2 and SIF, pH 7.4, respectively.

Key: SDA-3, and SDA-5, represents lumefantrine containing Eudragit RS100,and Eudragit E100 alone while SDB-3, and SDB-5 contained Urea in addition to the above mentioned polymers, in this ratios; $1: 2: 1,1: 3: 1,1: 2: 1: 1$ and 1:3:1:1, respectively. 
Table 3: Release kinetics of lumefantrine from pure drug, marketed tablets and solid dispersions

\begin{tabular}{|c|c|c|c|c|c|c|}
\hline \multirow[t]{2}{*}{ Formulation } & SGF pH 1.2 & SIF pH 7.4 & Zero order & Higuchi & \multicolumn{2}{|c|}{ Kosmeyer peppas } \\
\hline & at $12 \mathrm{~h}$ & at $12 \mathrm{~h}$ & & & $\mathrm{R}^{2}$ & $\mathrm{~N}$ \\
\hline SDA-3 & 65.7 & 13.9 & 0.9230 & 0.9980 & 0.5154 & 0.8770 \\
\hline SDA-5 & 67.0 & 16.2 & 0.9390 & 0.9954 & 0.6456 & 0.9321 \\
\hline SDB-3 & 78.0 & 14.4 & 0.9286 & 0.9931 & 0.6425 & 0.9870 \\
\hline SDB-5 & 68.9 & 13.3 & 0.9050 & 0.9918 & 0.5804 & 0.9170 \\
\hline Pure drug (LF) & 39.3 & 13.1 & 0.8499 & 0.9051 & 0.5196 & 0.7787 \\
\hline Coartem $^{\circledR}$ & 62.0 & 11.3 & 0.9061 & 0.9874 & 0.6065 & 0.9955 \\
\hline
\end{tabular}

\section{Anti-plasmodial activity}

The results of the anti-plasmodial studies of the formulations, in comparison with the pure drug and commercially available product are shown in Fig 4. The percentage reduction in parasite level was used to evaluate the pharmacologic anti-plasmodial activity of the formulations (SDA-3 and SDA-5) of the ternary batch, (SDB-3 and SDB-5) of the quaternary batch, pure drug and commercially available product in vivo. The chart obtained by plotting percentage reduction in parasitaemia against the batches are shown in Fig 6.The groups treated with the ternary (SDA-3 and SDA-5) and quaternary (SDB-3 and SDB-5) batch formulations showed higher, significant $(\mathrm{p}<0.05)$ and more reduction in parasite level when compared to those treated with the pure drug, which is an indication of improved performance produced by the solid dispersions.. Albeit, these batches showed a parasitic reduction but were insignificant $(\mathrm{p}>0.05)$ when compared to the animal group treated with the market brand coartem ${ }^{\circledR}$ (artemether and lumefantrine). Furthermore, in the animal groups treated with formulations of the ternary batches (SDA-3 and SDA-5), there was parasite clearance of $72.38 \%$, and $64.3 \%$ respectively; quaternary batches (SDB3 and SDB5) had $81.27 \%$ and $63.5 \%$ parasite clearance respectively. The group C treated with pure drug (lumefantrine) showed a $57.3 \%$ parasite clearance while the group D treated with a commercial sample of artemether and lumefantrine (coartem ${ }^{\circledR}$ ) showed a $72.72 \%$ parasite clearance and that of group E, the untreated group which received normal saline showeda parasite clearance of $26.4 \%$.

The haematological studies showed that there was a significant variation in the hematological parameters (PCV, Hb, RBC and WBC) due to the various effects of different treatments administered to the different groups as illustrated in Figs.5-6.

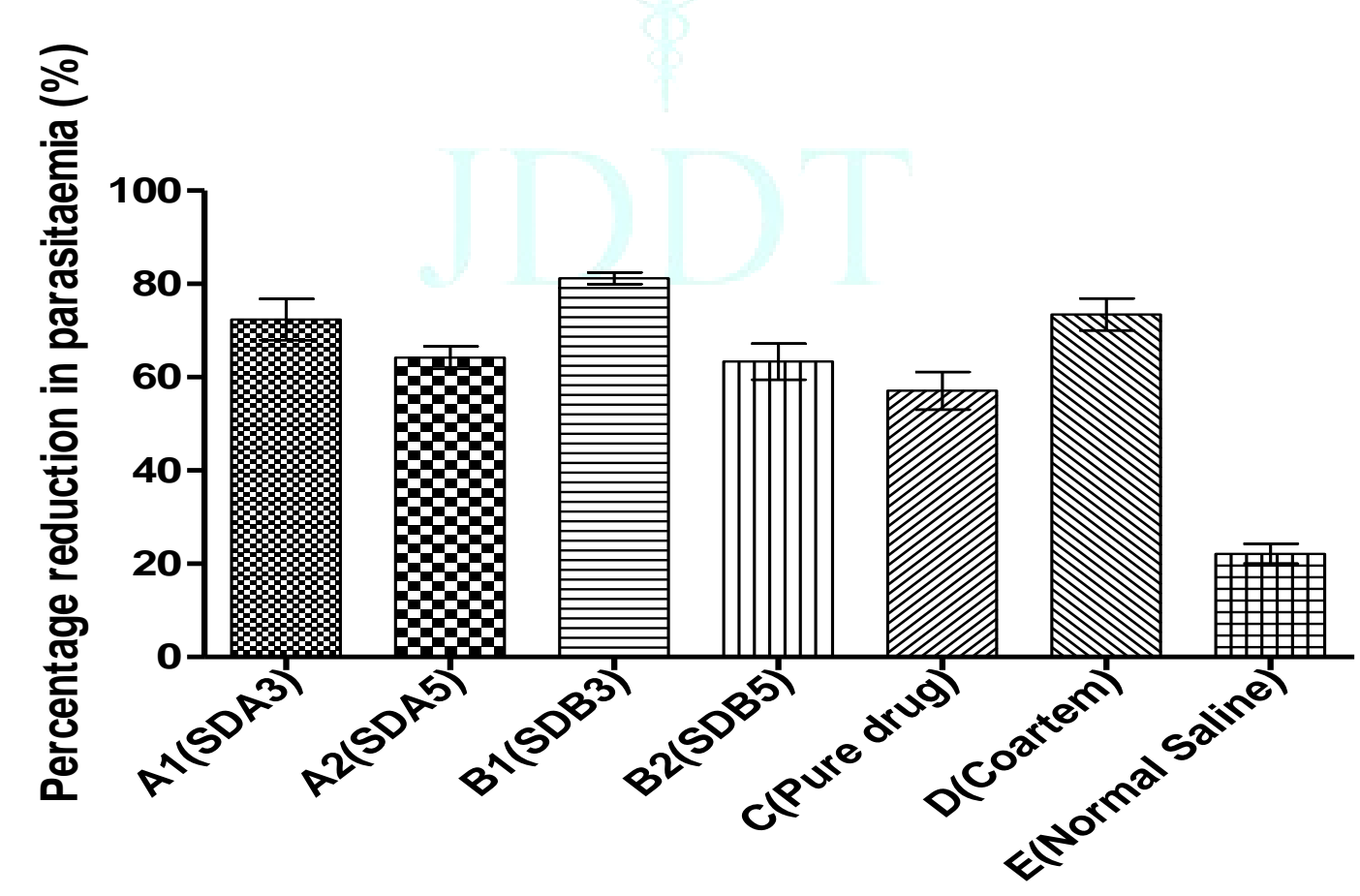

\section{Groups}

Fig. 4: Percentage (\%) reduction of the mice in the different groups A1(SDA3), A2(SDA5), B1(SDB3), B2(SDB5), C (pure drug, lumefantrine), D (market brand, coartem $^{\circledR}$ ) and $\mathrm{E}$ (control,normal saline) 

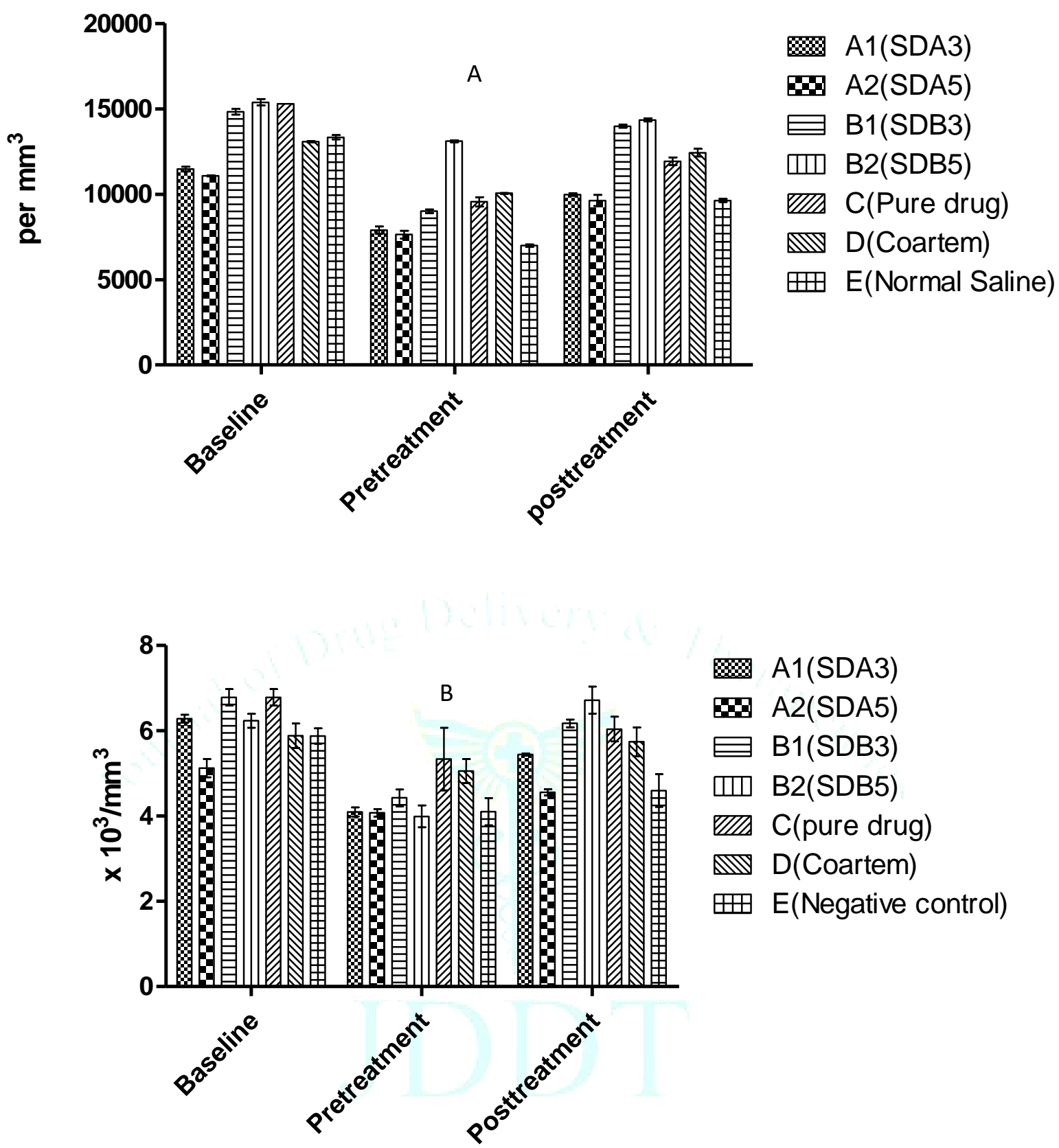

$\lll A 1(S D A 3)$

1 A2(SDA5)

$\equiv \mathrm{B} 1(\mathrm{SDB} 3)$

س $\mathrm{m}$ 2(SDB5)

एखि $\mathrm{C}$ (pure drug)

$D$ (Coartem)

巴(Negative control)

Fig. 5(A and B): depicts white blood cell (WBC) and red blood cell (RBC) of the mice respectively in groups A1, A2, B1, B2, C, D and $\mathrm{E}$ 


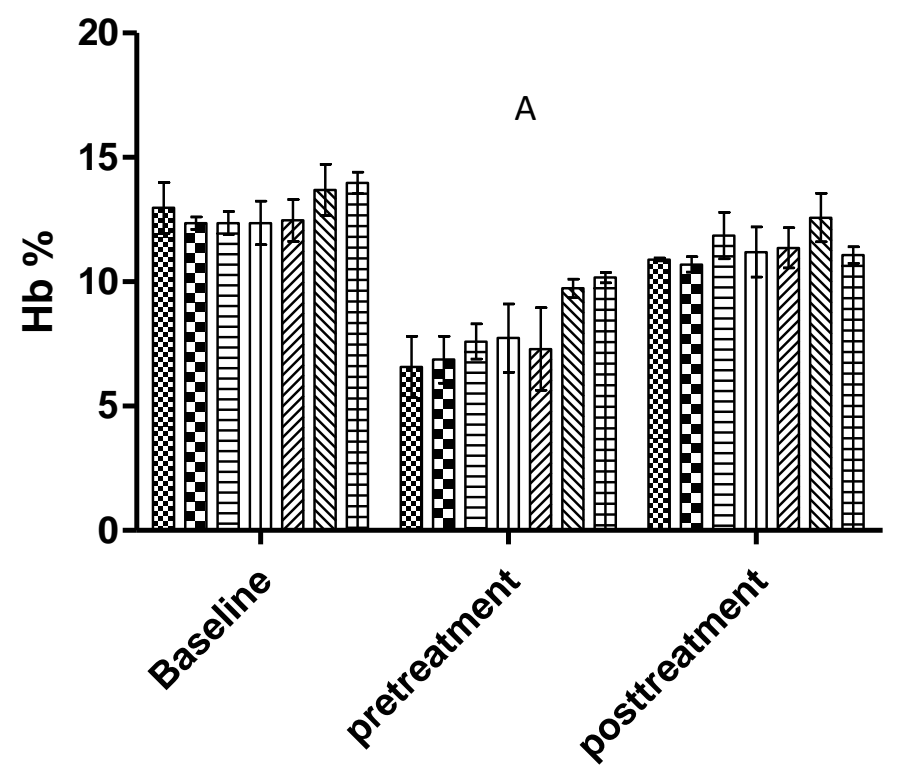
A1(SDA3)
1 A2(SDA5)
$\sqsupseteq \mathrm{B} 1(\mathrm{SDA} 3)$
때 B2(SDB5)
प्य $\mathrm{C}$ (pure drug)
$D$ (coartem)
巴一) E(Negative control

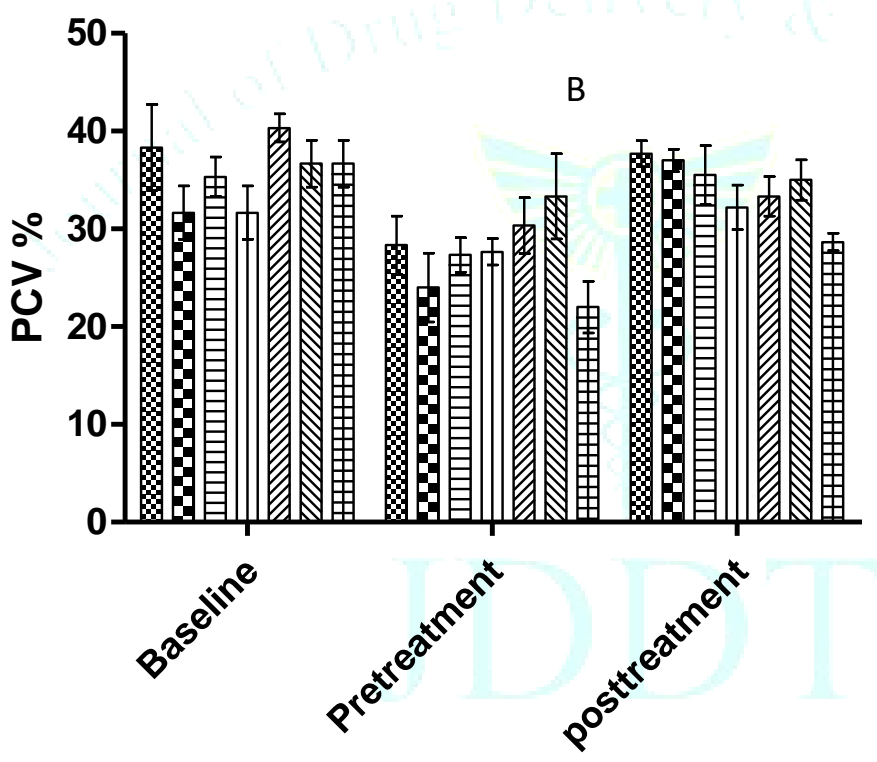
®1(SDA3)
$\infty$ A2(SDA5)
$\boxminus \mathrm{B} 1$ (SDB3)
미 B2(SDB5)
UDe (Pure drug)
$\mathrm{D}($ Coartem)
$\boxplus$ E(Negative control)

Fig. 6 (A and B): Depicts haemoglobin ( $\mathrm{Hb} \%$ ) and packed cell volume (PCV \%) of the mice respectively in groups A1, A2, B1, B2, C, D and E

\section{Histological studies}

The sections of the liver showed normal structures of the portal areas (hepatic artery, hepatic vein and bile ducts) were observed in group A (SDA-3) and G (uninfected). Sections of the liver collected from the animals in groups $B$ (SDA-5), C (SDB-3), D (SDB-5), E (pure drug) and F (commercial sample) showed mild to moderate degeneration of the hepatocytes as shown in Fig. 7. The lesions tend to involve primarily the hepatocytes in the centrilobular and midzonal areas of the hepatic lobules. The affected hepatocytes appear swollen, with multiple often coalescent tiny clear cytoplasmic vacuoles (white arrow) and also degenerated hepatocytes (black arrow).The sections of the kidney collected from the animals in groups $\mathrm{A}$ (SDA-3), B (SDA-5), C (SDB-3), D (SDB-5), E (pure drug), F (commercial sample) and $\mathrm{G}$ (uninfected) showed the normal renal histomorphology as depicted in Fig. 8. 

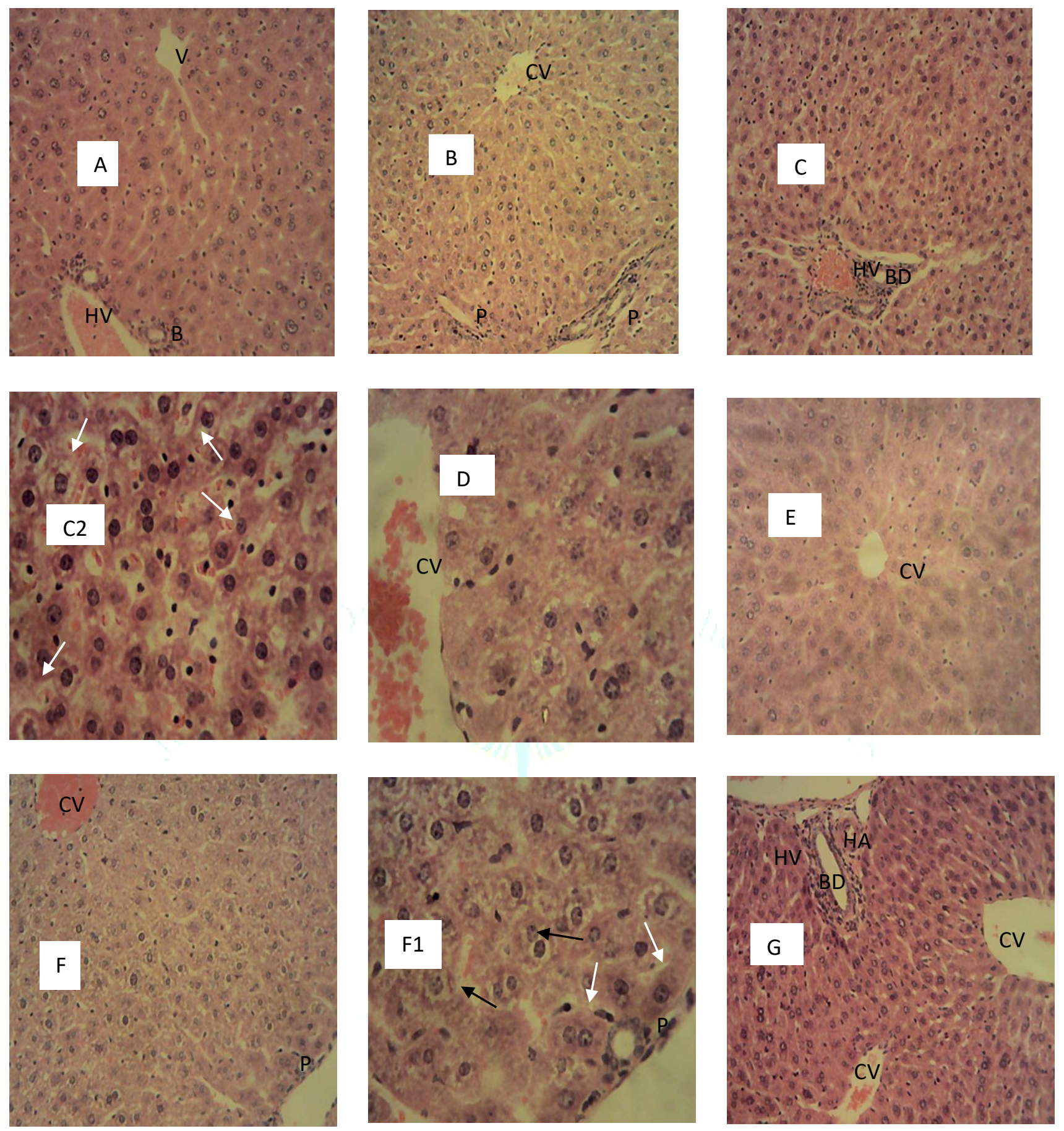

Fig. 7 (A-G): Photomicrographs of liver sections of mice treated with SDA-3, SDA-5, SDB-3, SDB-5, Pure drug sample, Commercial sample (Coartem $(\AA)$, and the uninfected respectively. $H$ and E X 400. Key: SDA-3, and SDA-5, represents lumefantrine containing Eudragit RS100, Eudragit E100 alone while, SDB-3, and SDB-5 contained Urea with the above mentioned polymers in this ratios; $1: 2: 1,1: 3: 1,1: 2: 1: 1$ and $1: 3: 1: 1$, respectively 

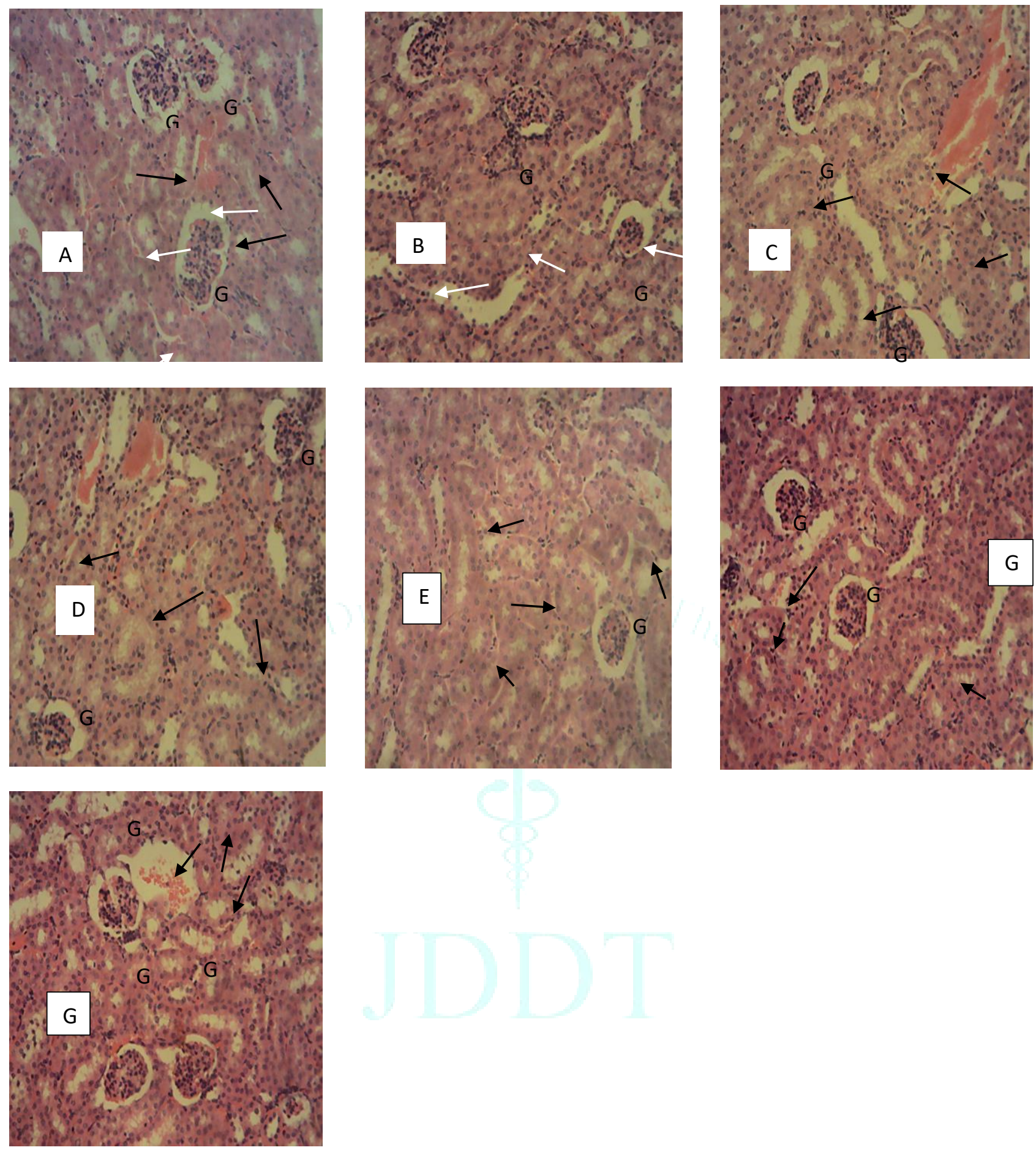

Fig. 8 (A-G): Photomicrographs of Kidney sections of mice treated with SDA-3, SDA-5, SDB-3, SDB-5, Pure drug sample, Commercial sample (Coartem ${ }^{\circledR}$ ), and the uninfected respectively. Key: SDA-3, and SDA-5, represents lumefantrine containing Eudragit RS100, Eudragit E100 alone while SDB-3, and SDB-5 contained Urea with the above mentioned polymers in this ratios; $1: 2: 1,1: 3: 1,1: 2: 1: 1$ and $1: 3: 1: 1$, respectively.

\section{DISCUSSIONS}

The percentage yield of lumefantrine SDs was determined to ascertain the losses incurred during formulation. A relatively low yield of the solid dispersions was obtained. The lower yield of solid dispersions with Eudragit RS 100 may be due to the fact that at high concentrations, it forms a rubbery mass which is very sticky and attaches to the container. It is also apparent that increased concentration of the Eudragit ${ }^{\circledR R S 100}$ and Eudragit ${ }^{\circledR E} 100$ was accompanied by increased yield in both the ternary and quaternary batches of the SDs. Hence, the small losses may have occurred during the process of preparation through weighing, mixing, transfers, or in the process of recovering the entire mass etc. ${ }^{17}$. The relatively higher drug entrapment in the quaternary system may be due to the wettability effect of urea which led to enhanced solubilization of the drug 19 . It also indicates that there was no much drug loss or the degradation (chemical) of drug during the formulation process $^{20}$. The reduced drug entrapment might also be attributed to the stickness of eudragit RS100 which led to some drug loss in the batches. 
The results of the stability studies obtained confirmed that there was no effect of storage on the physical properties of the SDS; thus, the drug remained stable in the formulation prepared with the carriers even after storage for a period of 6 months. The increase in solubility of lumefantrine in the formulated SDs could be attributed to the wettability effect of urea especially in the quaternary batches and also by the amorphous nature of the SDs ${ }^{19}$. The increased solubility of the drug in the SD can also be explained by improved dissolution of $\mathrm{SDs}^{21}$.

The photomicrograph images showed that drug morphology was clearly affected. SDs was successfully formed as they show morphologies distinct from that of the polymers and the pure drug sample. The mean particle size of the SDs significantly increased with increase in eudragit rs100 concentration. The reason may be due to the viscosity of medium which increases as the polymer concentration increases ${ }^{22}$. This might have resulted in the realization of larger particles.

DSC study was performed to confirm the physical state of lumefantrine in the SDs. The slight presence or total absence of a melting peak in the DSC of a solid dispersion indicates that the drug is partly or completely amorphous/ molecularly dispersed 23 . There is, however, a small additional endothermic peak at around $220{ }^{\circ} \mathrm{C}$, for urea, which may be attributed to the presence of a small amount of impurity in the material 24 . The DSC thermogram of SDA3, SDA-5, SDB-3 and SDB-5 batch of SDs showed a slight and decreased peak of the drug, with the peaks at $86.24{ }^{\circ} \mathrm{C}, 88.11$ ${ }^{\circ} \mathrm{C}, 89.55{ }^{\circ} \mathrm{C}$, and $91.58{ }^{\circ} \mathrm{C}$ respectively indicating that the drug was partly molecularly dispersed or partly amorphous in the carrier and also that there was greater LF miscibility. It also showed two peaks which were less than the melting peaking of the drugs indicating that lumefantrine were molecularly dispersed within the SDs. The improved solubility of the drug can be attributed to the amorphicity of the drug in the formulation. The termal attributes of lumefantrine were not found in the thermograms of the SDs, signifying the conversion of the drug and polymer into preferred amorphous state from crystalline state.

Based upon the data obtained from the dissolution studies, the amount of drug dissolved at specific time periods was plotted as percentage (\%) drug release versus time (min) curves. There was a sustained release of the drug from the SDs. In all cases, SDs recorded faster dissolution compared to the pure drug $(\mathrm{p}<0.05)$ and it was also insignificant when compared to the market brand (Coartem ${ }^{\circledR}$ ) ( $p>0.05$ ). Higher concentrations of the Eudragit ${ }^{\circledR}$ RS100 in the SDs of the ternary and quaternary batches prolonged the drug release due to its hydrophobic nature; this can be attributed to low permeability of the polymer, which posed a significant hindrance to fluid penetration and passive drug diffusion ${ }^{25}$. The possible mechanisms responsible for increased dissolution could be attributed to the wettability and solubilizing effect of the binary and ternary carriers which increased the drug solubility and impeded aggregated particles. As the soluble carrier dissolves, the insoluble drug gets exposed to dissolution medium in the form of fine particles for quick and faster dissolution ${ }^{26}$.

The in vitro release was fitted into several representations of the kinetic analysis such as zero order, first order, Higuchi and Peppas exponentials to define the drug release. The drug release from all the SDs followed the Higuchi order of release as revealed by their correlation coefficients values $\mathrm{R}^{2}$ as shown in (Table 3). Hence, it exhibited diffusioncontrolled release characteristics. From the values of the Korsemeyer-Peppas equation $(0.45<\mathrm{n}<0.89)$, it was observed that the release from the solid dispersions followed the non-fickian diffusion. This is an indication that drug release from the SDS was simply a desorption means from swelling polymers which followed the non- Fickian type of diffusion. Hence, these results indicate that lumefantrine could be effectively and efficiently delivered as solid dispersions based on blends of methacrylic acid polymers (Eudragit ${ }^{\circledR}$ RS100 and Eudragit ${ }^{\circledR}$ E100) and hydrophilic carrier, urea.

The therapeutic effects of the formulated SDs were tested on mice infected with Plasmodium berghei. The effect of the SDs on the parasite level of plasmodium-infected mice was assessed in comparison with both the pure drug sample and commercial product. It was obtainable from the results that the parasitic lowering effect was independent on the concentrations. The improved performance observed in the animal groups treated with the formulations corresponds with the improved dissolution observed. The haematological studies were carried out to determine the hematological parameters (PCV, Hb, RBC and $\mathrm{WBC}$ ) was shown indicating their values before treatment and after treatment. The values of the parameters reduced post inoculation with the parasite on day 3 , but showed a progressive stabilized increase on day 7 post-treatment. This efficacy was observed in other murine models, as described by Attama et al ${ }^{27}$.

The observations from the photomicrographs of the histological studies conducted on the liver of the mice from various groups showed normal hepatic histomorphology and also normal hepatic lobules consisting of normal hepatocytes arranged in radiating interconnecting cords around the central veins. The result of the kidney sections showed normal glomeruli (G) in thin Bowman's capsules (arrow) surrounded by a sea of normal renal tubules (proximal convoluted tubules, pars recta, distal convoluted tubules and collecting ducts) in both the cortex and the medulla. Also, normal renal interstitium consisting of thin, well-vascularized connective tissue matrix were observed. The observed changes are similar and consistent with the histological result of the study done on solid lipid microparticles of halofantrine ${ }^{28}$. The results of this study showed that administration of lumefantrine did not cause any significant damages to the mice with regards to the relative organ.

\section{CONCLUSION}

In this study, the SDs of lumefantrine was successfully prepared using Eudragit ${ }^{\circledR}$ RS100, E100 and urea advancing the solvent evaporation method. The aqueous solubility was improved and physicochemical characterization confirmed the presence of the drug (lumefantrine) in an amorphous state with improved dissolution characteristics. The SD system provided better control of drug release rate. Furthermore, lumefantrine loaded solid dispersion significantly $(\mathrm{p}<0.05)$ decreased parasitaemia in mice infected with Plasmodium berghei. The histological studies carried out also established the safety of the SD formulations as the result showed no evidence of deleterious side effects on major organs implicated in malaria. Overall, the improved physicochemical characteristics alongside the enhanced in vivo antimalarial efficacy of the SDs, established the pharmaceutical basis for recommending our formulation as a possible delivery system for lumefantrine. Further studies would seek to investigate the pharmacokinetics, antimalarial efficacy and safety of optimized formulation in higher animals.

\section{CONFLICT OF INTEREST}

The authors report no conflict of interest. 


\section{Acknowledgment}

The authors appreciate the assistance of Projex Laboratory for particle size analysis. The authors also wish to thank African-German Network of Excellence in Science (AGNES) Grant for Junior Researchers for funding the manuscript publication.

\section{REFERENCES}

1. Malaria [Internet]. [cited 2019 Jul 8]. Available from: https://www.who.int/news-room/fact-sheets/detail/malaria

2. Ashley, E.A., Pyae Phyo A., Woodrow C.J. Malaria. Lancet. 2018; 391(10130):1608-21.

3. Gahoi S., Jain G.K., Tripathi R., Pandey S.K., Anwar M., Warsi M.H, Singhal M., Khar, R.K, Ahmad, F.J. Enhanced antimalarial activity of lumefantrine nanopowder prepared by wet-milling DYNO MILL technique. Colloids Surfaces B Biointerfaces [Internet]. 2012; 95:16-22. Available from: http://dx.doi.org/10.1016/j.colsurfb.2012.01.047

4. Van, V.M., Brockman, BG A. Randomized comparison of artemether-benflumetol and artesunate-mefloquine in treatment of multi drug-resistant falciparum malaria. Antimicrob Agents Chemother. 1998; 42:135-9.

5. Omari, A.A., Gamble C., Garner, P. Artemether-lumefantrine for uncomplicated malaria : a systematic review. 2004; 9(2):1929.

6. Farnet, A., Ursing, J., Tolfrenstam, T., Rono, J., Karlsson, L S.E., et al. Artemether-lumefantrine treatment failure despite adequate lumefantrine day 7 concentration in a traveler with plasmodium falciparum malaria after returning from tanzania. Malar J. 2012;11,176.doi:10.1186/1475-2875-11176.

7. Colombo, M., de Lima Melchiades G., Michels, L.R., Figueiró, F., Bassani, V.L., Teixeira, H.F., Koester L.S. Solid Dispersion of Kaempferol: Formulation Development, Characterization, and Oral Bioavailability Assessment. AAPS PharmSciTech. 2019; 20(3).

8. Chio, WL R.S. Pharmaceutical applications of solid dispersion systems. J Pharm sci. 1971; 60:281-302.

9. Leuner, C D.J. Improving drug solubility for oral delivery using solid dispersions. Eur j Pharm BioPharm. 2000; 50:47-60. https://doi.org/10.1016/S0939-6411(00) 0007.

10. Vo, C.L., Park, C L.B. Current trends and future perspectives of solid dispersions containing poorly water-soluble drug. Eur J Pharm Biopharm. 2013; 85:799-813.

11. Choi, J.J.S., Lee S.E., Jang W.S., Byeon, J.C. Tadalafil solid dispersion formulations based on PVP? S-630: improving bioavailability in rats. Eur J Pharm Sci. 2017; 106:152-8.

12. Patil, S., Suryavanshi, s., Pathak, S., Sharma, S., Patravale V. Evaluation of novel lipid based formation of Artemether and lumefantrine in murine malaria model. Int J pharm. 2013; 455:229-234. doi: 10.1016. J. ij Pharm. 2013.07.033.

13. Patel, K., Sarma, V V.P. Design and evaluation of lumefantrineoleic acid self nano emulsifying ionic complex for enhanced dissolution; Daru. 2013; 21,:27, doi:10:1186/2008-2231-217.

14. Garg, A., Bhalala. K., Tomar, D.S., Wahajuddin. In-situ single pass intestinal permeability and pharmacokinetic study of developed Lumefantrine loaded solid lipid nanoparticles. Int J Pharm [Internet]. 2017; 516(1-2):120-30. Available from: http://dx.doi.org/10.1016/j.ijpharm.2016.10.064

15. Fule, R., Dhamecha, D., Maniruzzaman, M., Khale, A., Amin, P. Development of hot melt co-formulated antimalarial solid dispersion system in fixed dose form (ARLUMELT): Evaluating amorphous state and in vivo performance. Int I Pharm [Internet]. 2015; 496(1):137-56. Available from: http://dx.doi.org/10.1016/j.ijpharm.2015.09.069

16. Song, Y., Zemlyanov, D., Chen, X., Su, Z., Nie, H., Lubach, J.W., et al. Acid-base interactions in amorphous solid dispersions of lumefantrine prepared by spray-drying and hot-melt extrusion using X-ray photoelectron spectroscopy. Int J Pharm [Internet]. 2016 Dec [cited 2019 Jun 21]; 514(2):456-64. Available from:

https://linkinghub.elsevier.com/retrieve/pii/S03785173163 06160

17. Reginald-opara, J.N., Attama, A.A., Ofokansi, K.C, Umeyor, C., Kenechukwu, FC. Molecular interaction between glimepiride and Soluplus 1 -PEG 4000 hybrid based solid dispersions : Characterisation and anti-diabetic studies. Int J Pharm [Internet]. 2015; 496(2):741-50. Available from: http://dx.doi.org/10.1016/j.ijpharm.2015.11.007

18. Ryley, J.F., Peters, W. The antimalarial activity of some quinolone esters. Ann Trop Med Parasitol. 1970; 64(2):20922.

19. Allagh, T.S., Anuemeka, O.O., Ofokansi, K.C., Kenechukwu. F.C., Isah, A.B. Formulation and evaluation of solid dispersions based on eudragit RS100 and PEG 8000 for improved delivery of trandolapril. African J Pharm Res Deve. 2012; 4(1):38-42.

20. Medarević, D., Cvijić, S., Dobričić, V., Mitrić, M., Djuriš, J., Ibrić, $\mathrm{S}$. Assessing the potential of solid dispersions to improve dissolution rate and bioavailability of valsartan: In vitro-in silico approach. Eur J Pharm Sci [Internet]. 2018; 124:188-98. Available from: https://doi.org/10.1016/j.ejps.2018.08.026

21. Dangre, P.V., Godbole, M.D., Ingale, P.V., Mahapatra, D.K. Improved Dissolution and Bioavailability of Eprosartan Mesylate Formulated as Solid Dispersions using Conventional Methods. 2016; 50 (3): S209-S217 (August). doi: 10.5530/ijper.50.3.31

22. Thireesha, B., Prasad, A.R., HPP, L. FORMULATION AND EVALUATION OF LORNOXICAM MICROSPONGES USING EUDRAGIT RS 100 AND EUDRAGIT RSPO. 2018; 11(10): 217221.

23. Kerc, J., Srcic, S. Thermal Analysis of glassy pharmaceuticals. Thermochim Acta. 1995; 248:81-95.

24. Guo, S., Wang, G., Wu, T., Bai, F., Xu J., Zhang X. Solid dispersion of berberine hydrochloride and Eudragit $₫$ S100:Formulation, physicochemical characterization and cytotoxicity evaluation. J Drug Deliv Sci Technol. 2017; 40: 21-27. doi: 10.1016/j.jddst.2017.02.003.

25. Raju, R.T., Khrodhi, G.M., Harigopa, S.S., Vabhar, S.A. PSG. Formulation and evaluation of transdermal drug delivery system for lercanidipine hydrochloride. Int J Pharm Tech Res. 2010;2(1):253-8.

26. Aulton, M.E. The science of dosage form design. Churchill, Livingstone, London. 2008;pp.

27. Attama, A.A., Kenechukwu, F.C., Onuigbo, E.B., Nnamani, P.O., Obitte, N., Finke, J.H., et al. Solid lipid nanoparticles encapsulating a fluorescent marker (coumarin 6) and antimalarials - Artemether and lumefantrine: Evaluation of cellular uptake and antimalarial activity. Eur J Nanomedicine. 2016; 8(3):129-38

28. Ogbonna, J.D.N., Kenechukwu, F.C., Nwobi, C.S., Chibueze, O.S., Attama, A.A. Formulation, in vitro and in vivo evaluation of halofantrine-loaded solid lipid microparticles. Pharm Dev Technol. 2015; 20(8):941-8. 